
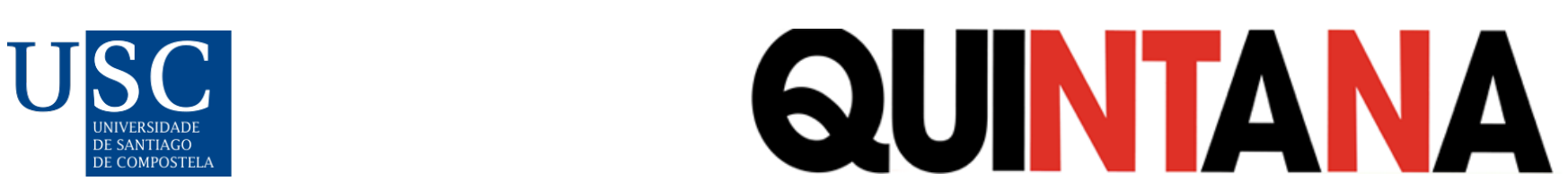

Quintana: revista do Departamento de Historia da Arte, (20), 2021. ISSN-e: 2340-0005

https://doi.org/10.15304/quintana.20.8053

Tema

\title{
VIAJES TRANSFORMADORES DE PERSONAJES EN EL CINE DE ICÍAR BOLLAÍN
}

TRANSFORMING TRAVELS OF CHARACTERS IN ICÍAR BOLLAÍN'S CINEMA

\author{
José Luis Sánchez Noriega, a(iD \\ ${ }^{1}$ Universidad Complutense de Madrid, España \\ a noriega@ucm.es
}

\section{Resumen}

El movimiento, inherente a la categoría de viaje, es central en el cine, tanto en la forma expresiva del dispositivo cinematográfico como en los géneros y temas de los relatos de ficción. En algunos cineastas como Icíar Bollaín en el viaje predomina la cualidad de la transformación en los personajes, tanto cuando se trata de huidas o búsquedas personales, emigración por supervivencia o mejores condiciones de vida, como cuando lleva a un territorio alejado por el modo de vida y el sistema cultural.

Palabras clave: viaje; Icíar Bollaín; road movie; cine español.

\begin{abstract}
Movement, inherent to travel as a category, is central to cinema, both in the expressive form of the cinematographic device and in fictional stories genres and themes. Some prominent filmmakers such as Icíar Bollaín show the transformational character arc related to the journey, both when it comes to personal searches or migration, and when it leads to a distant territory removed by the way of life and the cultural system.
\end{abstract}

Keywords: journey; Icíar Bollaín; road movie; spanish cinema.

En última instancia, todo viaje se desarrolla en un espacio y tiempo, que definen unas coordenadas cuya progresiva modificación da cuenta de un movimiento o traslación. Sobre la centralidad del espacio y el tiempo en la experiencia humana ya nos advirtió Immanuel Kant al señalarlos como formas puras de la intuición sensible, formas a priori del conocimiento y condiciones para la percepción de lo fenoménico. Tan decisivos son para el ser y estar de los humanos en el mundo que no hay representaciones fuera del espacio y del tiempo, de suerte que en la práctica podríamos decir que sin ellos no existe el mundo porque no podría ser conocido.

Pero no hay que ir tan lejos si tenemos en cuenta que, ya desde las primeras vistas de los Lumière, el cine como mecanismo de representación / expresión viene definido por estas dimensiones; la propia denominación del invento señala la especificidad del movimiento que no es sino la captación de un espacio en un tiempo. En esos primeros años del cinematógrafo Ricciotto Canudo 
hace hincapié en esa perspectiva y habla del «sueño de inmortalidad en el espacio y en el tiempo» (Manifiesto de las siete artes 1911) en su comprensión del cine como «arte de síntesis total» frente a otras formas de creación que no aúnan espacio y tiempo, aunque Richard Wagner abogara por la ópera como obra de arte total (Gesamtkunstwerk) por su capacidad de integrar música, teatro y artes visuales. El desarrollo de la fotografía con el fusil fotográfico y los demás mecanismos de cronofotografía tratan de incorporar la (cuarta) dimensión del tiempo a la representación del espacio que es la imagen bidimensional; espacio y tiempo se plasman de forma inmediata en el movimiento, por ello resultan ejemplares piezas exhibidas en la sesión inaugural del 28 de diciembre de 1895 como La salida de los obreros de la fábrica Lumière y Llegada de un tren a la estación de la Ciotat que sitúan la cámara en el enclave adecuado para la captura del espacio y, sobre todo, eligen una «acción» que sea filmable en el tiempo de menos de un minuto que permite el negativo de la época.

Además de esta dimensión estructural, semiótica, el movimiento alcanza su plenitud en los desarrollos argumentales del viaje, tan ricos en la Historia del Cine como el género de aventuras, la road movie, crónicas de migración y conquista del territorio, radiografías sociales a través de la mostración de espacios humanos, laboriosas búsquedas de tesoros, viajes de exploración espacial, persecuciones o huidas en el cine de acción, historias de exilios o utopías de viajes en el tiempo. De forma más metafórica podríamos añadir "viajes" al conocimiento, de acceso a la edad adulta, de maduración sentimental y sexual, de aprendizaje, etc. En cualquier caso, el recorrido por un territorio físico implica un viaje de mayor entidad psicológica, emocional o moral en los personajes, frecuentemente un viaje a la adquisición del conocimiento y de la madurez. Con estas reflexiones no queremos plantear ninguna propuesta epistemológica omnicomprensiva que exija los apriorismos kantianos plasmados en el movimiento-viaje como categorías desde las que abordar gran parte del cine; nos basta con señalar su condición medular tanto en el propio lenguaje fílmico como en la práctica histórica. Ello es más patente en la estética de determinados cineastas, ya desde clásicos como John Ford ${ }^{1}$.

De entrada, llama la atención que en un cine, como el español, relativamente renuente a explorar otros espacios, en la decena de largometrajes dirigidos por Icíar Bollaín la mitad transcurre en parte o en su totalidad en el extranjero (espacio extraño a los personajes) y únicamente dos historias - Te doy mis ojos (2003) y Mataharis (2007) - presentan una construcción dramática sin un viaje significativo. No es casualidad que el primer largometraje de la directora — Hola, estás sola? (1995) - comience como viaje de huida y de búsqueda por distintos lugares para terminar como viaje interior al pasado y a la reconciliación con la infancia deficitaria en afectos.

Hay un muy curioso antecedente, el corto Viajes con mi abuela (2002) en que la directora filma a un bebé de dos años, su hijo Lucas, descubriendo el mundo en un viaje en metro en compañía de Elena Pérez-Mínguez, madre de la cineasta. Prácticamente sin diálogos, esta breve pieza de tres minutos constituye una exploración del espacio físico y la actividad del suburbano, con el trasiego de personas y la experiencia para el bebé de ver la realidad desde el movimiento, de ahí la opción por posiciones de cámara desde los ojos del niño, que subrayan el lugar de aprehensión del mundo (Sánchez Noriega 2021, 170). 


\section{HUIDAS, BÚSQUEDAS Y EXPLORACIONES}

Preguntarse por las motivaciones de los personajes para iniciar un viaje permite comprender claves de valores y convicciones que funcionan como arquitectura ideológica de este cine.

Huida y búsqueda están unidas en Hola, estás sola? (1995) donde la Niña tiene una bronca con su padre, no acepta trabajar en la tienda y huye del domicilio familiar y de las obligaciones que se le exigen; pero el viaje que emprende con Trini — quien también ha de marcharse, expulsada de la vivienda alquilada - es de búsqueda, aunque no sepan muy bien ni lo ansiado ni lo necesitado: «En este caso el viaje sirve para la transformación, el conocimiento y la construcción de las mujeres jóvenes según parámetros de voluntad, libertad y deseo inhibidos en otras generaciones, viaje de huida sin rumbo para conjurar el vacío, en pos de una incierta felicidad» (Sánchez Noriega 2021, 196). El análisis que hace Cuadrado (2012) de esta película subraya la estructura del viaje; considera que se trata de un «viaje iniciático y sin retorno de dos jóvenes hacia la madurez y su correspondiente pérdida de la inocencia» $(2012,8)$ que contrasta con otros retratos literarios y cinematográficos de jóvenes en ese momento, con personajes más pasivos y estáticos. Para este autor, el viaje de Trini y Niña responde a una de las modalidades del viaje del héroe clásico, según categorización de Campbell: el elegido por propia voluntad, que tiene sus pruebas iniciáticas, aunque el resultado para esas jóvenes no sea la consecución de la madurez completa (ibidem 15-16).

En un primer impulso hedonista, las dos chicas van a Torremolinos, porque buscan sol y playa. Trabajan como animadoras de hotel para turistas jubilados, una dedicación poco gratificante que tiene sus días contados; por ello no es de extrañar su marcha a Madrid cuando Niña le dice a su amiga que su madre vive en la capital. Se revela, entonces, que más que aventuras o nuevas experiencias -y, por supuesto, más que un trabajo con que ganarse la vida-, la búsqueda emprendida es en pos de cariño, del afecto desinteresado y sin recompensa que otorga la familia: en el caso de Trini buscando una madre "de adopción” y en el de Niña con la agresividad contenida de quien se ha sentido abandonada y tiene muchos reproches que hacer.

El encuentro con la madre coincide con una relación de pareja en la que Niña desarrolla un rol maternal y protector hacia el extranjero que no sabe español. Las dos protagonistas emprenden otro viaje que ahora tiene el valor de la maduración del aprendizaje. Se van a la costa con la madre y un amigo (Pepe), y ponen en marcha un chiringuito: Niña tiene la decepción de dejar en el camino al extranjero, con ese primer aprendizaje doloroso de que no siempre es compatible el esfuerzo y el placer, aunque lo compensa con la prueba de amistad de Trini. El trabajo en el chiringuito, la decepción por la gestión económica y el engaño de Pepe enseña a las protagonistas las condiciones habituales de una sociedad competitiva y la rivalidad por el dinero y las relaciones sentimentales entre las personas.

El cuarto y último trayecto de las dos amigas es el regreso a Madrid con búsquedas de naturaleza emocional, motivadas por cierta sensación de vacío: la ausencia del novio en Niña y de un hijo que en Trini compense la falta de madre («ya que no he tenido madre, me apetece serlo»). Se trata de un desenlace no conclusivo como observa Guillamón-Carrasco para quien «el trayecto vital de las jóvenes aparece inacabado puesto que la narración construye un relato abierto, rechazando la clausura en términos clásicos y proponiendo la apertura como espacio desde el que repensar lo subjetivo, como un lugar desde el que enunciar, construir y redefinir el deseo» (Zecchi 2013, 69).

Un cuarto de siglo después, la misma Candela Peña encabeza el reparto de La boda de Rosa (2020) convertida en una mujer madura, madre y abuela, agobiada por el trabajo y los deberes familiares 
que, asimismo, emprende un viaje transformador. Esa madurez cambia la perspectiva del viaje, que ya no viene impulsado por un arrebato ni una búsqueda incierta, sino que es fruto de una reflexión serena a partir de la toma de conciencia de su situación de "mujer para todo" y de las palabras de promesa de matrimonio que ensaya una actriz y que ella quiere decirse a sí misma.

No se trata de un viaje largo, pero el cambio de espacio marca la ruptura con un estilo de vida («Dar al botón nuclear y partir de cero») y la apuesta por otro distinto. Abandonar la ciudad y trasladarse al pueblo de su infancia para recuperar el taller familiar es un gesto de "quemar las naves" que se simboliza con la inopinada boda de Rosa consigo misma y unas promesas que concretan el programa de transformación ${ }^{2}$.

También se puede interpretar ese viaje como un regreso al mundo gratificante de la infancia y la nostalgia de la madre y la vida familiar. El taller de costura con los objetos que lo caracterizan se revela como territorio acogedor; en el clímax del relato es el lugar donde se dirime el conflicto y los hermanos y la hija de Rosa apoyan su decisión de cambio de vida. El viaje hasta ese espacio está motivado por la convicción de una transformación que, básicamente, es un "reencantamiento", la apuesta por un vitalismo gratificante para la persona desde la realización de su deseo y su vocación, sin imposiciones externas que cercenen la voluntad soberana.

Bastante diferente es el periplo de El olivo (2016), más utópico que funcional. En clave de épica voluntarista los protagonistas realizan un aparatoso viaje desde el Mediterráneo español a Alemania en busca del árbol milenario que le fue arrebatado a la finca familiar y que para Alma tiene el valor alegórico del sentido de la tierra y del patrimonio secular de la familia, como explica el abuelo ${ }^{3}$ y como señala la directora al llamar la atención sobre el expolio de árboles de hasta 2000 años para convertirlos en objetos de lujo y decoración (Castro 2016). El viaje a Düsseldorf está destinado al fracaso porque es una gran mentira - de Alba a Alca y Rafa, de este al dueño del camión ${ }^{4}$ - aunque en el camino se produce un rearme moral y un proceso de maduración que lleva a una toma de conciencia, eleva la autoestima de los personajes, potencia su sentido de la solidaridad... y desarrolla relaciones personales más sólidas en esos jóvenes insatisfechos con sus vidas por los empleos precarios y el sentimiento de que se han burlado de ellos.

El viaje es un tránsito entre dos espacios físicos, sociales y humanos muy contrastados. Transcurre desde la finca y la casa familiar que representan el esfuerzo, la economía productiva, el respeto al legado de la tierra, la sostenibilidad, el medioambientalismo sin retóricas y la austeridad previas a todo discurso ecologista... y el edificio de acero y cristal de la gran ciudad ubicada en el centro económico e industrial de Europa donde una empresa se reviste como "naturalista" para su negocio energético.

Ello otorga al estrambótico viaje en camión una dimensión simbólica pues «no es tanto la historia épica de un viaje como la ensoñación, puesta en imágenes, de un personaje al que la vida aún no ha castigado con sus límites» (Armas 2016). Esa dimensión se refuerza con la réplica de la estatua de la Libertad neoyorkina que se encuentran en el viaje y que Alca carga en el remolque, una figura colocada en el jardín de unos nuevos ricos que lo han estafado. La ulterior destrucción de la estatua posee un valor catártico, pues supone la puesta en escena del rechazo de los jóvenes al sistema capitalista regido por la lógica del enriquecimiento y de la especulación financiera. Por tanto, el viaje es también una especie de órdago desde el Sur al Norte, desde los empobrecidos a los ricos, de la vida en comunión con la Naturaleza a los disfraces medioambientalistas de la lógica capitalista. 


\section{EMIGRANTES Y TRANSTERRADOS}

Viajes de emigración o por razones de trabajo son los que emprenden los protagonistas del documental En tierra extraña (2014) y de la ficción basada en hechos reales Yuli (2018); aunque hay notables diferencias en las condiciones laborales y la situación en cada caso, lo relevante es que se trata de emigrantes en sentido estricto: personas que huyen del desempleo o buscan uno más cualificado. De ordinario, el viaje del emigrante carece de cualquier atractivo propio del viaje turístico y presenta, como primera dificultad, la inserción en un medio social o cultural nuevo.

En el documental de 2014 se hace un retrato de los emigrantes de la crisis de 2008: jóvenes muy cualificados profesionalmente que han de ganarse la vida con ocupaciones de menor nivel y remuneración, aunque valoran su empleo y la apertura de la sociedad británica, y perciben que es preferible el trabajo en Escocia que el paro en España. No obstante, se subraya la dificultad del idioma, la aspiración a un trabajo cualificado, el sentimiento de desarraigo, la soledad por la ausencia de familia o amigos, o la propia condición de emigrantes ${ }^{5}$. Este documental de testimonios presenta una manifiesta dimensión política en cuanto los emigrantes trascienden sus historias particulares para profundizar en las causas de la crisis económica y ver su situación como resultado concreto de la gestión de nuestros gobernantes; se abunda en el papel que los bancos y los poderes económicos y políticos han tenido en España durante la crisis, así como en los efectos sociales de la corrupción de los dirigentes políticos.

La dimensión emocional de la emigración es muy fuerte; queda patente la soledad, el vacío de la ausencia de la familia y la nostalgia por la tierra, lo que se expresa en el título En tierra extraña, tomado de la canción homónima de Concha Piquer o, más probablemente, del tema $E l$ emigrantepopularizado por Juanito Valderrama ${ }^{6}$. Un testimonio llega a plantear que el idioma y las costumbres del país cambian el modo de pensar, relacionarse y estar de los jóvenes; que la identidad llega a transformarse y, al final, no se sabe cuál es la "tierra extraña", de suerte que los trabajadores adquieren la condición de transterrados o neonómadas. Deveny $(2017,198-199)$ llama la atención sobre este aspecto como uno de los temas fundamentales de la película y explica que los emigrantes españoles en Escocia ubican su situación en un contexto global, tanto por los compañeros de Bulgaria, Finlandia, Portugal o Polonia que trabajan en Edimburgo como por las imágenes de archivo que testimonian la llegada de inmigrantes de África y Latinoamérica a España o, incluso, de los africanos saltando la valla de la frontera de Melilla. Sobre esta situación el sociólogo Joaquín García Roca subraya que la gran revolución antropológica en marcha lleva, en el futuro inmediato, a que las instituciones sean transfronterizas, aunque ahora se justifica la xenofobia y el racismo con discursos excluyentes hacia el "otro".

A ese vacío y sentimiento de amputación que vive el emigrante hace referencia el tema del guante solitario, presente en el cartel y en el rótulo inicial («Como un guante al que le han arrebatado su otra mitad»). La primera secuencia muestra la curiosa e intrigante recogida en la calle de guantes perdidos y desparejados que son colocados en una verja para hacerlos visibles; luego se explica que se trata de una acción de The Blender Collective, un grupo de españoles afincados en Edimburgo, convertida en metáfora de la condición de los jóvenes emigrantes y que acaba por ser símbolo de protesta política con el lema «Ni perdidos ni callados». El guante, además, es una pieza que protege ante el frío y la intemperie, por ello deviene signo muy directo de protección contra la soledad, y la acción de los miembros de ese colectivo con los guantes es una escenificación del ejercicio voluntarioso de autoestima. Esta suerte de performance política remite también a la propia película, 
que habría de ser considerada como instrumento de comprensión de la realidad, como señala en su crítica Troncóniz (2014) ${ }^{7}$. En fin, el documento audiovisual da cuenta del valor terapéutico y político de la palabra con los testimonios de emigrantes, ubica su situación en un contexto global y hace memoria de otras migraciones, y señala la situación económica, las desigualdades y la pobreza como causas de esas migraciones.

Podríamos considerar que, en clave documental, En tierra extraña es una exploración de la situación de las mujeres que emigran a otro país o a otra cultura que ya estaba presente en la ficción Flores de otro mundo (1999) donde Patricia (dominicana), Mari Rosi (bilbaína) y Milady (cubana) viajan a un pueblo de la Castilla profunda, condenado a formar parte de la España vacía, para recomponer su vida familiar. Más que laboral, el viaje a ese pueblo de la "caravana de mujeres" se explica por la estrategia del lugar de evitar la despoblación y el interés de las mujeres en encontrar pareja: cada una tiene una perspectiva y una motivación en ese viaje y en las relaciones sentimentales con los lugareños. Patricia logra la integración desde su apertura a otros valores y estilo de vida y con la colaboración de Damián y Gregoria, que terminan por aceptar el "mundo" que trae consigo. Por el contrario, la diferencia entre Mari Rosi y Alfonso es insalvable porque, aun siendo dentro del mismo país, el medio rural y el urbano difieren de forma radical. Milady está en tránsito hacia Italia y ha engañado a Carmelo quien, además, muestra una conducta machista y controladora que anula a cualquier mujer.

En el relato autobiográfico Yuli la infancia del bailarín cubano viene marcada por el viaje de su madre y de su hermana al exilio / emigración, probablemente más por razones económicas que políticas, al igual que sucede más tarde con un amigo que, en la "crisis de los balseros" (1994), va a poner en riesgo su vida echándose a la mar. Pero el gran viaje del bailarín Carlos Acosta, Yuli, es el traslado a Londres con la oportunidad de incorporarse al English National Ballet: para él no sólo es una ocasión extraordinaria de desarrollo profesional y de cambiar todo tipo de condiciones de un país pobre por uno rico. Para Yuli, descendiente de esclavos afroamericanos, de clase obrera y una exigente y conflictiva educación a sus espaldas, se trata de la consecución de sus metas profesionales y de un viaje al éxito social. Su padre le anima a que acepte el contrato en Londres con el argumento de que «cuando a un negro le dan un premio como este lo agarra con las dos manos y no lo suelta ni que lo maten».

Pero ese viaje es agridulce por la nostalgia de la familia, el dolor por no ayudar a su hermana enferma y, en fin, la esquizofrenia que vive debido al contraste entre el éxito profesional y la infelicidad emocional. El viaje de regreso a Cuba tras la lesión en el pie supone una toma de conciencia con la realidad de jóvenes que quieren dejar el país, la corrupción, la discriminación racial y el sentimiento de que su trayectoria le ha llevado a un doloroso desarraigo: «Cuando llevas tanto tiempo ya no eres ni de aquí ni de allá» dice Yuli a su novia. Aún tendrá que hacer otros viajes (Houston, Londres) antes de regresar a La Habana y crear su propia compañía, en un último regreso no exento de problemas. Por tanto, los viajes en Yuli funcionan como etapas en la carrera artística del bailarín y, al mismo tiempo, se plasma el fuerte contraste entre el espacio económico y político de Cuba y un exterior más indefinido y referido en exclusiva a esa carrera.

\section{DE LA TOMA DE CONCIENCIA A LA TRANSFORMACIÓN}

Aunque los personajes desarrollen un trabajo en los países a los que viajan, lo decisivo de los protagonistas de También la lluvia (2010) y Katmandú, un espejo en el cielo (2011) no son las 
condiciones económicas y laborales, sino las dificultades en ese nuevo contexto geográfico, cultural, social y político, que pone en cuestión la escala de valores o los presupuestos culturales de esos personajes.

El viaje de los mexicanos, argentinos y españoles a Bolivia de También la lluvia es por motivos profesionales y se reduce a una estancia de unas semanas para el rodaje de una película ambientada en los primeros años de la colonización. Sin embargo, el viaje virtual al siglo XVI y la realidad actual de la "guerra del agua" suponen una toma de conciencia sobre la dominación política, económica, cultural, lingüística y religiosa, pues se establece un paralelismo en las dos situaciones como, entre otros, exponen Camacho Salgado y González Ortega (2017). Así como en el pasado Bartolomé de las Casas o Antonio de Montesinos defendieron la dignidad de los indios y se opusieron al maltrato, en el presente los cineastas acaban apoyando las protestas contra la privatización del agua en Cochabamba; en efecto, «la voz indígena suprimida durante la colonización resurge con fuerza en el siglo XXI para cuestionar el legado histórico de la misma y rechazar el discurso hegemónico de las corporaciones multinacionales que pretenden privatizar el agua» (Osorio 2015, 524).

Las diferencias culturales entre los cineastas de varios países y los indígenas bolivianos se plasma con fuerza en la secuencia en que las mujeres deberían ahogar en el río a los bebés: para los primeros es una mera ficción representable sin pudor ni consecuencias, mientras las bolivianas se niegan porque para ellas probablemente remita a sucesos históricos similares o, en todo caso, hay un límite en la teatralización, incluso aunque se realice con muñecos, sin riesgo alguno para los niños. Asimismo se evidencia el paternalismo y el desprecio implícito hacia los indígenas en las condiciones económicas del trabajo en el cine. La lógica de la dominación y del clasismo también está presente en el interior de la sociedad boliviana, con los dirigentes políticos que desprecian a los indígenas y los presentan como ignorantes que no entienden la "modernización".

Cuando el conflicto se agudiza, los extranjeros toman actitudes contrapuestas: mientras el director Sebastián y los actores abandonan la ciudad y dejan de comprometerse, a pesar de sus dudas iniciales ${ }^{8}$ y del intento de que el actor Daniel se desentienda de la "guerra del agua", el productor Costa se alinea con los indígenas con el riesgo de arruinar la película. También la lluvia articula diferentes niveles del discurso que plasman las distancias culturales y políticas, como estudia Paszkiewicz (2012) y como recogemos en Sánchez Noriega $(2021,288)$ al señalar que

Pasado y presente, ficción e historia, reflexión y realidad, se articulan en el texto fílmico mediante diversos recursos. Se contrapone la ficción fílmica del pasado - tanto en los ensayos como en el rodaje-y la realidad del presente; y es frecuente la mediación de imágenes videográficas (reportaje sobre el rodaje, pero también noticias de televisión sobre la guerra del agua) que establecen una distancia reflexiva.

Ello refuerza un mecanismo de autoconciencia que renuncia a la transparencia cinematográfica para indagar en la visión de fondo en que coinciden las representaciones del pasado y el presente de la ficción.

Por tanto, además de viaje por el tiempo, el de También la lluvia tiene bastante de reto moral o toma de conciencia que cuestiona los valores del Occidente hegemónico en el presente y en el pasado. En una primera fase, el descubrimiento conlleva una operación de colonización del pensamiento y del lenguaje, de las conductas y costumbres, y del conjunto de la visión del mundo de los indígenas. Precisamente la película insiste en la posesión de la palabra como mecanismo de contrapoder a través de la figura de Hatuey / Daniel quien con la palabra cuestiona el sometimiento al Papa y a la Monarquía, rechaza el bautismo, actúa como portavoz de las protestas contra la privatización del agua y desvela los engaños del productor ${ }^{9}$. Tanto en el siglo XVI como ahora, 
los extranjeros buscan la dominación cultural-ideológica y la rentabilidad económica en el Nuevo Mundo.

Pero en una segunda fase, el conocimiento del “otro", del diferente e inicialmente incomprensible, conlleva una redefinición de la propia identidad que «se afirma cuando se asume la diferencia, en cuanto lo exótico del otro y su confinamiento al caos y a la barbarie sirven para fijar los límites del yo. La caracterización diferencial de los personajes delimita un perímetro simbólico de identidad que los protege de lo desconocido», como afirma Lorente $(2019,27)$ desde categorías desarrolladas por Emmanuel Levinas y Tzvetan Todorov. A partir de ahí es posible la empatía y el compromiso con el "otro", como vemos en los personajes de Costa y María, que se implican en las protestas con los riesgos personales que asumen por el clima de violencia.

En Katmandú, un espejo en el cielo el viaje de una española a Oriente reviste otras características, pues viene motivado por la voluntad altruista y el compromiso de cooperación solidaria con un país pobre. Por tanto, en cierto modo este relato representa la continuación de También la lluvia con la respuesta que dar a la toma de conciencia y la inmersión en un medio cultural nuevo.

El contraste que experimenta la protagonista Laia entre Oriente y Occidente presenta diversas dimensiones: en los valores y concepciones ante la educación, las relaciones familiares, las creencias y el pensamiento mágico, la equiparación de sexos, el sistema de castas, el trabajo infantil, la corrupción de funcionarios, etc., aunque en ambas sociedades se constata similar marginación en las niñas, que reciben una educación autoritaria y traumáticos abortos clandestinos de chicas jóvenes. Por tanto, se trata de un viaje de inmersión en otras coordenadas culturales y sociales que cuestionan los propios valores, señalan límites de la acción del voluntariado y conllevan el esfuerzo de aceptar costumbres aunque con el horizonte de cambiarlas. Al igual que en También la lluvia, el dominio de la palabra y la herramienta del idioma muestran la distancia cultural: en este caso se presupone que el inglés es una lengua franca, universal. Pero este es un presupuesto occidental que hace crisis cuando se aprecia que las palabras o la verbalización de las ideas no tienen equivalentes exactos.

En efecto, Laia se encuentra con prácticas tradicionales de difícil aceptación, como la de aislar a las niñas 12 días en una habitación oscura cuando les llega la primera regla, el trabajo infantil en detrimento de la escolarización, la prostitución, la exclusión de los "intocables" o el despojamiento del nombre / identidad de Bimala que pasa a ser "La niña que carga a [su hermano] Jaram". Pero también la europea ha de cuestionar sus prejuicios, como cuando aprende que el matrimonio de conveniencia le beneficia a ella y no al nepalí, y, sobre todo, la distinta perspectiva de lo que debe ser la educación. Laia trata de enseñar a los niños «a ser libres, a elegir y a ser ellos mismos» y no a seguir «estúpidas tradiciones que les atan y no les dejan crecer»; por el contrario, la nepalí Sharmila aboga por una educación en que aprendan a «cuidarse unos a otros, a respetar a sus mayores» $\mathrm{y}$ pone el ejemplo de a su madre, que siendo viuda y sin hijos que la cuiden, nunca le falta comida, ni un saludo ni personas que la escuchen... Es decir, que el ideal occidental no sólo resulta inviable en ese medio social, sino también mucho menos deseable y práctico para el futuro de los niños. El relato plasma la paradoja de que la presencia de la europea en el colegio aumenta la cuota que tienen que pagar los niños.

Por todo ello, el personaje de Laia, protagonista absoluta del relato, vive un viaje transformador que está en el centro del relato; por ello la directora Icíar Bollaín valora

el cambio personal, hay una parte de peli que me gusta mucho que es lo que tiene de viaje-experiencia, un viaje que te cambia y te descubre por dentro al mismo tiempo que descubres otro lugar. Ella va a aprendiendo a fuerza de equivocarse, de entender la otra cultura, que es otro mundo. Me pareció muy bonito también algo que le pasa a 
mucha gente: el encontrarse con uno mismo y echar raíces en un lugar tan distinto, que tu lugar resulta que está a 6.000 kilómetros de tu casa. Descubres que tu lugar no es donde has nacido sino ese otro que tiene que ver poco contigo (Melero Abascal 2012).

Los viajes son un mecanismo narrativo esencial en las historias del cine de Icíar Bollaín. Siempre están justificados de forma muy realista, tanto por la motivación como por los descubrimientos, situaciones vividas o cambios que experimentan los personajes. Se omiten los viajes de placer y otros debidos al azar o a cambios de escenario encaminados a la gratificación del espectador.

Como se puede apreciar, en gran medida estos viajes están protagonizados por mujeres, al igual que la mayoría de las historias de la filmografía de Icíar Bollaín. Incluso en el documental En tierra extraña, que podía ofrecer un mayor equilibrio en las personas entrevistadas, se opta por privilegiar la voz y situación de las mujeres españolas emigrantes en Edimburgo. Con distintas edades y situaciones, las mujeres de Hola, estás sola? y La boda de Rosa buscan cariño en sus vidas, mayor reconocimiento de los demás y un modo de vida más gratificante en el terreno sentimental.

El viaje del emigrante resulta muy duro, tanto por las condiciones económicas y la distancia cultural de su destino como por las heridas emocionales debidas a la soledad o la ausencia de la familia. A estos argumentos, se añaden en Yuli las motivaciones y riesgos del éxodo económicopolítico. Los viajes a espacios culturalmente más distantes (América Latina, Asia) ponen en cuestión los valores y presupuestos culturales o ideológicos de los personajes que, en última instancia, han de redefinir su identidad y cambiar sus paradigmas en la interacción con el "otro". Como en la gran tradición de la literatura de viajes, en el cine de Icíar Bollaín los personajes que salen de su casa no son los mismos que los que regresan: el periplo ha supuesto cambios sustanciales en su forma de ver el mundo debido a la interacción con personas de otras culturas y valores. Este hecho es muy coherente con una filmografía de carácter humanístico en la que los personajes están por encima de las historias y, por tanto, en la que sucesos como los viajes son relevantes en la medida en que construyen a esas representaciones de seres humanos y muestran su evolución.

\section{REFERENCIAS}

Armas, Jonay. “El olivo.. Caimán. Cuadernos de Cine 49 (mayo 2016): 114.

Camacho Salgado, Laura y González Ortega, Nelson. "Descolonizando la historia colonial de Bolivia en el siglo XXI: Negociacíon de las fronteras entre el pasado, presente y futuro en la pelicula Tambiénla lluvia (2010)." En N. Gonźalez Ortega (comp.). Bolivia en el siglo XXI: trayectorias históricas y proyecciones políticas, económicas y socioculturales, 311-341. Madrid: Iberoamericana Vervuert, 2017. https://doi. org/10.31819/9783964566584-017

Castro, Cristina. “Entrevista: Icíar Bollaín. 'Nuestro modelo de sociedad está construido contra la naturaleza'” Greenpeace Magazine 17 (2016): 12-13.

Corujo Martín, Inés. "Un árbol en tiempos de crisis: ecocŕitica y politica ecologica en El olivo de Ićiar Bolláin." Letras Hispanas 13 (2017): 222-230. (Disponible en https://www.worldlang.txstate.edu/letrashispan as/previousvolumes/vol13.html)

Cuadrado, Agustín. "Viaje al fondo de la juventud: Neoheroínas urbanas en la España de los noventa en Hola, ¿estás sola?, de Icíar Bollaín.” Crítica Hispánica XXXIV, no. 2 (2012): 7-28.

Deveny, Thomas. “En tierra extraña (Icíar Bollaín): testimonio y llamada a acción.” En F. López Criado (ed.), El arte en un mundo en crisis. La literatura, el cine y la prensa como instrumentos de transformación social, 195-202. Santiago de Compostela: Andavira, 2017. 
Lorente, Núria. "Retóricas y estéticas del descubrimiento de América en También la lluvia (2010) de Icíar Bollaín." Quaderns de Cine 14 (2019): 21-31. https://doi.org/10.14198/qdcine.2019.14.03

Melero Abascal, Silvia. “Icíar Bollaín: «Dirigir es abrir ventanas».” 21 RS, 31 enero 2012. https://www.21rs. es/es/revista-21/1128_Iciar-Bollain-Dirigir-es-abrir-ventanas.html

Osorio, Myriam. “Discursos en contienda: También la lluvia de Icíar Bollaín." Revista Iberoamericana LXXXI, núm. 251 (abril-junio 2015): 523-537. https://doi.org/10.5195/reviberoamer.2015.7278

Paszkiewicz, Katarzyna. "Del cine épico al cine social: el universo metafilmico en También la lluvia (2010) de Ićiar Bolláin." Lectora 18 (2012): 227-240.

Sánchez Noriega, José Luis. Icíar Bollaín. Madrid: Cátedra, 2021.

Tassi Teixeira, Rafael y Cogo, Denise. "Diáspora, interculturalidade e memoria em En tierra extraña (Icíar Bollaín, 2014).” En M. Marcos Ramos (ed.), IV Congreso Internacional Historia, Arte y literatura en el cine en español y en portugués (CIHALCEP 2017), 502-517. Salamanca: Centro de Estudios Brasileños, 2017. https://doi.org/10.1590/1982-2554232967

Troncóniz, Luis F. de. “En tierra extraña.. Caimán. Cuadernos de Cine 33 (diciembre 2014): 64.

Zecchi, Barbara (coord.). Gynocine. Teoría de género, filmología y praxis cinematográfica. Zaragoza / Amherst: Prensas de la Universidad de Zaragoza / University of Massachusetts, 2013.

Notas

1 Desde el regreso a Ítaca narrado en la Odisea el viaje ha sido un recurso constante en la literatura universal con historias que recogen el nomadismo, figuras de aventureros, pícaros y héroes épicos, viajeros y exploradores de nuevos mundos y tierras ignotas. Desde la novela de caballerías a los cuadernos de bitácora y los libros de viajes, se crean formatos específicos para esta literatura.

2 Este es el discurso de transformación: «He decidido comprometerme conmigo misma. Porque para que te traten con respeto y amor te tienes que respetar y amar tú la primera. Prometo respetarme, cuidarme; prometo escucharme, prometo perdonarme, prometo hacer lo que me haga bien a mí. Prometo preguntarme a mí misma primero antes de preguntar lo que quieren los demás. Prometo llevar a cabo mis sueños y mis deseos; prometo quererme con todo mi corazón todos los días de mi vida. También quiero renunciar a poner mi felicidad en manos de los demás. $Y$, por último, renuncio a ser obediente».

3 El abuelo se resiste y razona a sus hijos: «Ese árbol no es nuestro, se ha heredado de los abuelos, de los abuelos de los abuelos, de padres a hijos y así... Si yo vendo ese olivo y os doy el dinero, a la semana no tendréis ni olivo, ni dinero ni restaurante. Ese árbol no tiene precio, ese olivo es sagrado y ese árbol es mi vida; y vosotros queréis quitarme mi vida». Una provechosa reflexión sobre los significados del olivo en esta película se encuentra en Corujo, "Un árbol en tiempos de crisis".

4 Este es uno de los ejes del relato y del diagnóstico sobre la sociedad: «Del discurso del filme se desprende un ensayo sobre las formas y manifestaciones de la verdad y la mentira, de las falsificaciones y los engaños, de la manipulación y la corrupción, y de la forma suprema de dominación que consiste en arrebatar la palabra, de someter condenando al silencio (... ) La mentira no se ciñe a comportamientos individuales, sino que permea una sociedad que vive por encima de sus posibilidades, juega sucio en los negocios, dejando impagos, o alienta prácticas bancarias de riesgo, cuando no se entrega directamente en la corrupción de comprar voluntades políticas para laminar la legalidad». Sánchez Noriega, Icíar Bollaín, 331-333.

$5 \mathrm{Y}$, como ya dejamos escrito, estos emigrantes «Rechazan cualquier consideración de su estancia como aventura u oportunidad de mejora profesional y se ven a sí mismos como los magrebíes o latinoamericanos inmigrantes en España, aunque disfruten del respaldo legal de ser ciudadanos europeos. Como queda subrayado en la secuencia donde Gloria habla por videoconferencia con su familia, la emigración de los jóvenes es resultado de una sociedad de desigualdades y corrupción». Sánchez Noriega, Icíar Bollaín, 313).

6 La letra dice «Me voy hacer un rosario con tu diente de marfil / para que pueda besarlo cuando este lejos de ti. / Sobre sus cuentas divinas / hechas con nardo y jazmín / rezaré pa' que me ampare / aquella que esta en San Gil // Adiós mi España "quería” / dentro de mi alma te llevo "metía” / aunque soy un emigrante/ jamás en 
la vida yo podré olvidarte. // Cuando salí de mi tierra / volví la cara llorando, / porque lo que mas quería / atrás me lo iba dejando / llevaba por compañera / a mi virgen de San Gil /un recuerdo y una pena / y un rosario de marfil // Adiós mi España "quería" (....) // Yo soy un pobre emigrante / y traigo a esta tierra extraña / en mi pecho un estandarte / con la alegría de España / con mi patria y con mi novia / y mi virgen de San Gil / y mi rosario de cuentas / yo me quisiera morir»

7 La crítica comienza estableciendo un paradigma importante de hermenéutica del filme: «En momentos de crisis sabemos que el gran público tiende a refugiarse en el arte buscando la anestesia que combata la depresión social, pero también instrumentos que le permitan comprender esa realidad».

8 Costa argumenta a la cineasta mexicana que quiere hacer un documental «Yo no soy una ONG. Esto no es asunto mío» a lo que ella replica «Pero estás aquí», lo que significa que el viaje y la estancia en otro territorio y otra cultura compromete de forma irreversible a las personas.

9 Como explicita Lorente ("Retóricas y estéticas del descubrimiento," 24) «las coacciones en el uso, tanto del lenguaje, como de las formas de trasmisión occidentales del saber, no solo supusieron la imposición de un sistema de comunicación diferente. También conllevaron la instauración de un sistema de conciencia que se aplicaría a todos los aspectos de la vida y que ejercería un modelo de disciplina y control que persiste hasta nuestros días. Con la llegada de Colón a las costas americanas, la cultura indígena y la vida en sí misma quedarían reducidas al sistema social de comunicación occidental, articulado como un sistema capaz de disciplinar a los individuos recién sometidos y como una forma de control sobre su vida, legitimada hasta nuestros días». 